\title{
Role of biomass spread in vegetation pattern formation within arid ecosystems
}

\author{
Sally Thompson, ${ }^{1}$ Gabriel Katul, ${ }^{1}$ and Sean M. McMahon ${ }^{1}$ \\ Received 12 February 2008; revised 10 June 2008; accepted 6 August 2008; published 29 October 2008. \\ [1] The spatial organization of biomass resulting from plant-water feedbacks in arid \\ ecosystems, "patterned vegetation," provides a macroscopic signal of nonlinear plant- \\ water interactions and ecosystem health. Current models that reproduce such patterning \\ assume diffusive biomass movement but do not account for realistic transport through \\ seed dispersal. An adaptation of an existing three-equation model that accounts for the \\ interactions between overland flow, subsurface flow, and biomass dynamics is used to \\ investigate the impact of representing biomass spread with realistic dispersal kernels \\ (a "kernel-based method"). Model results indicate that dispersion behavior changes the \\ spatial organization of vegetation, destabilizing the regular patterns predicted by diffusion- \\ based models. The kernel-based approach provides a closer match to power spectra \\ derived from a remotely sensed image of patterned vegetation when compared to their \\ diffusion-based counterpart. Potential feedbacks between the presence of spatial patterns \\ and selection of optimal seed dispersal length scales are also investigated.
}

Citation: Thompson, S., G. Katul, and S. M. McMahon (2008), Role of biomass spread in vegetation pattern formation within arid ecosystems, Water Resour. Res., 44, W10421, doi:10.1029/2008WR006916.

\section{Introduction}

[2] Self-organization of vegetation into regular patterns has been observed in arid and semiarid ecosystems worldwide, across a wide variety of plant species and forms, and on a range of soil types [Tongway and Ludwig, 2001; Rietkerk and van de Koppel, 2008]. Patterned vegetation was first noticed by air in the 1950s [Clos-Arceduc, 1956], and the intriguing landforms generated extensive field studies that identified many of the important commonalities of patterned landscapes: an arid to semiarid climate, high-intensity rainfall, minimal soil type differences between vegetated and bare zones beyond those immediately attributable to the presence of vegetation, noticeable crusting in the bare zones, and a dependence on a topographic gradient that resulted in a transition from anisotropic banding patterns to isotropic "labyrinth," "gap," and "spotted" patterns as the slope declined to less than 0.2\% [d'Herbes et al., 2001; Galle et al., 2001; Tongway and Ludwig, 2001; Rietkerk et al., 2002].

[3] These features suggest that patterns arise as an emergent feature of nonlinear plant-water interactions, where water availability increases beneath vegetation, as a result of the suppression of growth of biological soil crusts [Belnap et al., 2001], the presence of roots and macropores increasing infiltration rates and potentially plant canopies shading the soil surface, reducing soil evaporation [Scholes and Archer, 1997]. The net result is a locally elevated soil moisture resource in the proximity of vegetation [Bromley et al., 1997; Valentin et al., 1999]. An extensive literature

\footnotetext{
${ }^{1}$ Nicholas School of the Environment and Earth Sciences, Duke University, Durham, North Carolina, USA.
}

Copyright 2008 by the American Geophysical Union. 0043-1397/08/2008WR006916\$09.00 has examined the importance of patterned landscapes as resource harvesting structures [Greene et al., 2001; Mauchamp et al., 2001; Thiery et al., 2001; Rietkerk and van de Koppel, 2008], but only in the last decade has theoretical attention been given to these landscapes as dynamic nonlinear systems in which the self organization of vegetation can be generically studied despite large differences in ecosystem types [Thiery et al., 1995; Klausmeier, 1999; HilleRisLambers et al., 2001; von Hardenberg et al., 2001; Lejeune, 2002; Rietkerk et al., 2002; Gilad, 2004; Rietkerk et al., 2004]. Initially this approach was driven by phenomenological models of facilitation and competition between vegetation structures [Lefever and Lejeune, 1997] then through coupling biomass and soil moisture budgets explicitly [Klausmeier, 1999; von Hardenberg et al., 2001]. However, it has largely been the inclusion of surface water transport in these models that reproduced realistic patterning length scales, and these three-component models represent the current state of the art with respect to process simulation of patterned landscapes [Rietkerk et al., 2002; Gilad, 2004; Yizhaq et al., 2005]. The existing model frameworks have been refined with respect to the importance of stochasticity in rainfall [D'Odorico et al., 2006a, 2006b; Ursino and Contarini, 2006] and aspects of plant physiology [Ursino, 2007] pertinent to photosynthesis, respiration, and stomata response to mean vapor pressure deficit [Kefi et al., 2008]; as well as soil properties [Ursino, 2005]. A critical finding from this effort has been that patterned landscapes are bistable states that may undergo "catastrophic ecosystem shifts" to a desertified state from which the previous patterned condition cannot be recovered [Rietkerk et al., 2004; Kefi et al., 2007a, 2007b]. Research into patterned landscapes has therefore shifted perspective from the original questions concerning the maintenance and function of these intriguing systems to research that aims to use the 


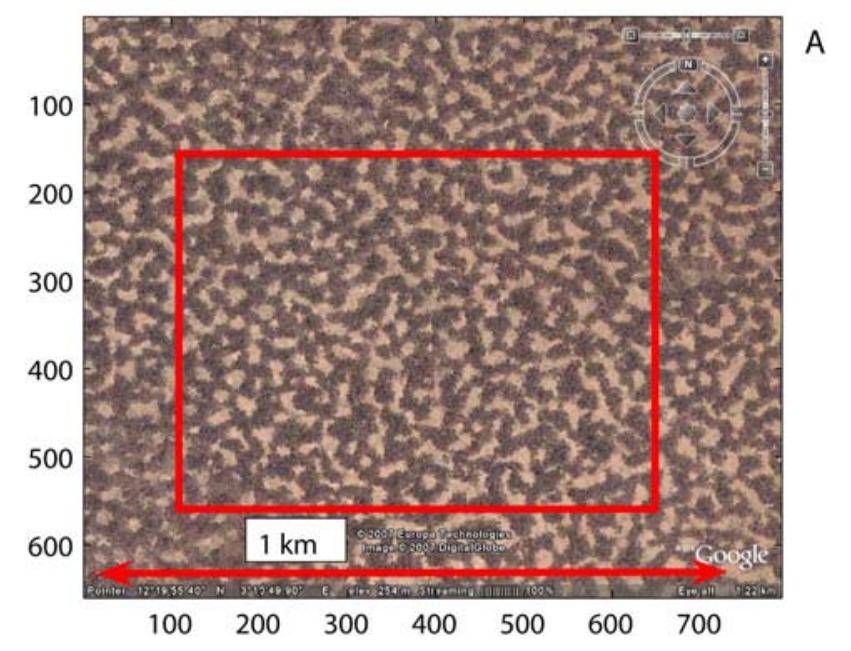

A
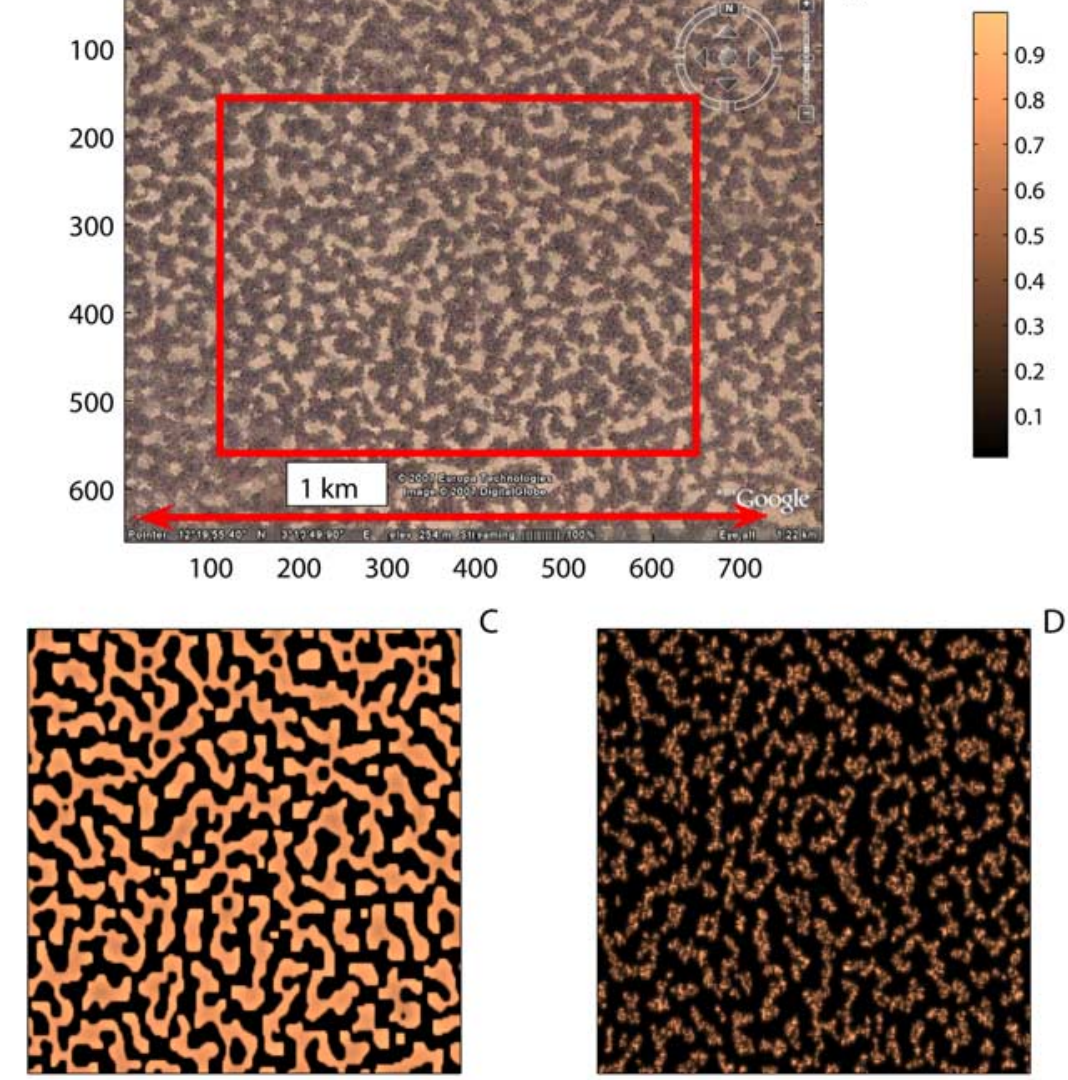

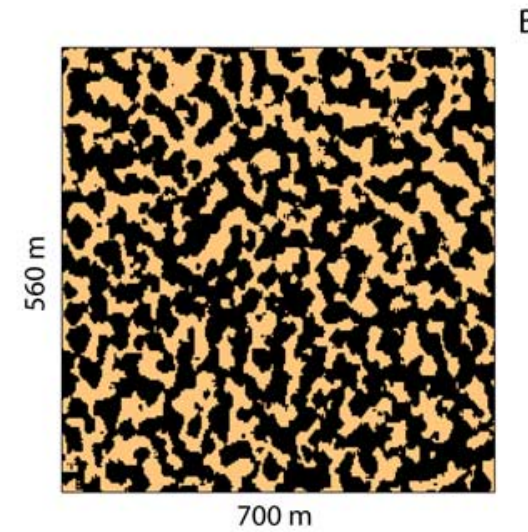

$B$

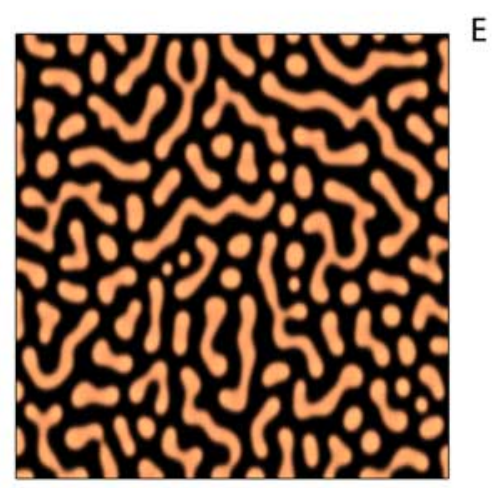

Figure 1. (a) An image taken from Google Earth at $12^{\circ} 19^{\prime} 55.40^{\prime \prime} \mathrm{N}$ and $3^{\circ} 10^{\prime} 49.90^{\prime \prime} \mathrm{E}$ in Niger on 28 January 2006. (b) A subsampling and smoothing of the image, which was then used as the initial condition for the simulation results (Figures 1c-1e). (c) The results from the dispersion model, (d) the diffusion model with stochastic soil properties, and (e) the original diffusion model. The parameter values used were $c=10, g_{\max }=0.05, k_{1}=5, D_{p}=0.1, \alpha=0.2, k_{2}=5, W_{o}=0.2, r_{w}=0.2, D_{w}=0.1$, $D_{o}=100, R=1, d=0.23$.

condition of the emergent patterns as an indicator of ecosystem health. A critical component of research into these patterns involves developing the capacity to infer the state of the ecosystem given "observable" patterns of vegetation. Such inference is of necessity based upon models that contain the appropriate representation of the key processes occurring within the ecosystem.

[4] In evaluating the state of the science in this manner, two observations can be made about key knowledge gaps. The first is that despite extensive refinement of the models used, an evident difference remains between modeled and real vegetation patterns, in that the former are smooth, while the latter display a conspicuous degree of disorder (Figures 1a and 1e). The second is that the representation of plant movement, critical to the formation of a pattern, has not been considered in detail, but instead has been represented via diffusion in almost all models formulated, or accounted for phenomenologically by representation of long-range interactions [D'Odorico et al., 2006a]. Diffusion results in a representation of biomass movement that is localized and depends upon biomass gradients to determine the relative rate of transport. In contrast, real plant population movement, assuming sexual reproduction, is driven by the production and transport of seeds. These observations lead to an initial question, namely, is the disorder observed in real patterns representative of underlying randomness at small scales as is known to exist in soil properties, or might it arise because biomass movement is less diffusive than its representation in current models?

[5] To answer this question, we couple a "dispersal kernel," defined as the probability distribution of seed distances from their parent source [Clark, 1998; Clark et al., 1998, 1999] to existing pattern formation models as an alternative to diffusion. Dispersal kernels describe both local and nonlocal movement and are independent of biomass gradients. The use of a dispersal kernel differs somewhat from previous kernel-based models [Lefever and Lejeune, 1997; D'Odorico et al., 2006b] in which the kernel encodes the interactions responsible for local facilitation and long-range inhibition of vegetation growth, i.e., the genesis of pattern formation [Murray, 2002]. Instead, the dispersal kernel approach solely dictates the rates and spatial scales of biomass transport, while the facilitative and inhibitory processes are determined by the interactions of biomass and water, just as in the diffusion-based model. The coupling of seed dispersal kernels with pattern-forming models can address several questions fundamental to understanding vegetation patterns in arid and semiarid 
systems: Can patterns be maintained in the absence of a diffusive representation of biomass? What is the "direction" of pattern evolution, toward or away from more continuous cover? Finally, could feedbacks exist between dispersal ecology, soil moisture redistribution, and pattern formation in these highly organized ecosystems?

[6] The paper proceeds by outlining the basic features of dispersal ecology in arid ecosystems first, then addressing the incorporation of a seed dispersal kernel into a model of pattern formation, which is used to address the questions outlined above.

\section{Seed Dispersal}

[7] The dispersal of seed determines ecological characteristics of plants and their communities, such as gene flow and the genetic structure of populations [van der Pijl, 1972; Cain et al., 2000], the survival and success of subsequent generations of plants, rates of expansion into new terrain and the spatial distribution of plants at multiple spatial scales in terms of habitat, range, and spatial organization within the landscape [Clark, 1998; Clark et al., 1998, 2001]. Dispersal is broadly characterized by a canonical length scale over which seeds move and by a dispersal vector that transports them. The length scales of dispersal vary from highly localized $(<1 \mathrm{~m})$ to long distance (LDD, $\left.10^{0}-10^{2} \mathrm{~m}\right)$. Transporting vectors change the statistical properties of kernels, with exponential kernels induced by simple ballistics, longer range and often leptokurtic kernels associated with wind or water dispersal, and with the stochastic, anisotropic and potentially nonrandom transport by insects, birds, or animals often difficult to represent via kernel approaches [van der Pijl, 1972; Ellner and Shmida, 1981; Fragoso, 1997; Russo et al., 2006; Thompson and Katul, 2008].

[8] Dispersal in desert plants typically occurs over short length scales [Davidson and Morton, 1984; Chambers and MacMahon, 1994] with many species' seeds lacking adaptations to promote dispersal (atelechory) or exhibiting adaptations that limit dispersal (antitelechory) [van der Pijl, 1972; Ellner and Shmida, 1981]. Many desert perennial species rarely propagate from seed, and asexual reproduction is common [Abrams, 1988; Thiombiano et al., 2003]. The dispersal ecology of species comprising patterned vegetation is variable, and has not been comprehensively studied [Montana et al., 2001]. Some species, such as Combretum micranthum (West Africa), appear to have adaptations for secondary wind dispersal, with roundwinged seeds that "tumble" along the ground [Midgley, 1998]. Other species, such as Acacia aneura (Australia), are dispersed primarily by ants [Davidson and Morton, 1984]. Several of the species involved in pattern formation have the capacity to reproduce asexually (e.g., Combretum micranthum, Guiera senegalensis, Pleuraphis (formerly Hilaria) murtica) [Couteron and Lejeune, 2001; Thiombiano et al., 2003; R. Uchytil, Pleuraphis mutica, in Fire Effects Information System, Fire Sciences Laboratory, Rocky Mountain Research Station, Forest Service, U.S. Department of Agriculture, 1988, available at http:/www.fs.fed.us/ database/feis/plants/graminoid/plemut/all.html]. However, seedling recruitment is often described within patterned sites suggesting that seed dispersal is an important process in these landscapes. Where soil crusts are well formed, they may pose an obstruction to seedling recruitment [Prasse and Bornkamm, 2000] and indeed Montana et al. [2001] show that where the slope of the ground is significant $(>0.2 \%)$ the seed bank tends to lie within vegetated areas, as a result of secondary transport by runoff from the interband. This study, however, considers only cases where there is no significant slope, so the velocities of surface water and seed transport by water are relatively low and oriented toward local vegetated sites. Secondary transport thus effectively shortens dispersal length in this scenario and is not considered explicitly here. For the case of a slope grade large enough to impose a preferential direction of flow, alternative and anisotropic descriptions of seed transport are needed.

\section{Methods}

\subsection{Ecohydrological Model}

[9] The study is based on an adaptation of a simple spatial model of arid ecosystem vegetation-water relations developed by HilleRisLambers et al. [2001] and Rietkerk et al. [2002]. The original model equations are

$$
\frac{\partial P}{\partial t}=c g_{\max } \frac{W}{W+k_{1}} P-d P+D_{p} \Delta P
$$

where $P$ is the plant biomass in $\mathrm{g} \mathrm{m}^{-2}$;

$$
\frac{\partial W}{\partial t}=\alpha O \frac{P+k_{2} W_{o}}{P+k_{2}}-g_{\max } \frac{W}{W+k_{1}} P-r_{w} W+D_{w} \Delta W,
$$

where $W$ is the soil water depth in $\mathrm{mm}$; and

$$
\frac{\partial O}{\partial t}=R-\alpha O \frac{P+k_{2} W_{o}}{P+k_{2}}+D_{o} \Delta O
$$

where $O$ is the surface water depth in $\mathrm{mm}$. The model parameters are $c$ (water uptake to plant growth relation, $\mathrm{g} \mathrm{mm}^{-1} \mathrm{~m}^{-2}$ ), $g_{\max }$ (maximum specific water uptake $\mathrm{mm}$ $\mathrm{m}^{2} \mathrm{~g}^{-1}$ day $^{-1}$ ), $k_{1}$ (half saturation constant of water uptake, $\mathrm{mm}), d$ (death rate, day $\left.{ }^{-1}\right), D_{p}$ (biomass diffusion coefficient, $\mathrm{m}^{2}$ day $^{-1}$ ), $\alpha$ (maximum infiltration rate day ${ }^{-1}$ ), $k_{2}$ infiltration (half saturation constant $\mathrm{g} \mathrm{m}^{-2}$ ), $W_{o}$ (water infiltration in absence of plants, []), $r_{w}$ (timescale of water loss due to evaporation and drainage, day ${ }^{-1}$ ), $D_{w}$ (soil water diffusion coefficient, $\mathrm{m}^{2}$ day $^{-1}$ ), $R$ (precipitation, $\mathrm{mm}$ day $\left.^{-1}\right) ; D_{o}$ (surface water diffusion coefficient, $\mathrm{m}^{2}$ day ${ }^{-1}$ ) and $\Delta$ is the Laplacian, $\left(\frac{\partial^{2}}{\partial x^{2}}+\frac{\partial^{2}}{\partial y^{2}}\right)$, where $x$ and $y$ are Cartesian coordinates.

[10] The model represents a positive feedback between water and carbon where infiltration relates to biomass density in a Michaelis-Menten sense [Briggs and Haldane, 1925]. Soil water uptake increases with vegetation biomass, resulting in a negative feedback due to competition for the limited available water. Spatial movement of water and biomass is represented as diffusive. The model produces spatial patterns with a characteristic wavelength following the typical spot-labyrinth-gap sequence as water availability increases. This pattern sequence is shown in Figure 2c for the original model equations.

[11] To refine the representation of biomass transport, the diffusion term in the $P$ equation is replaced by a convolution 

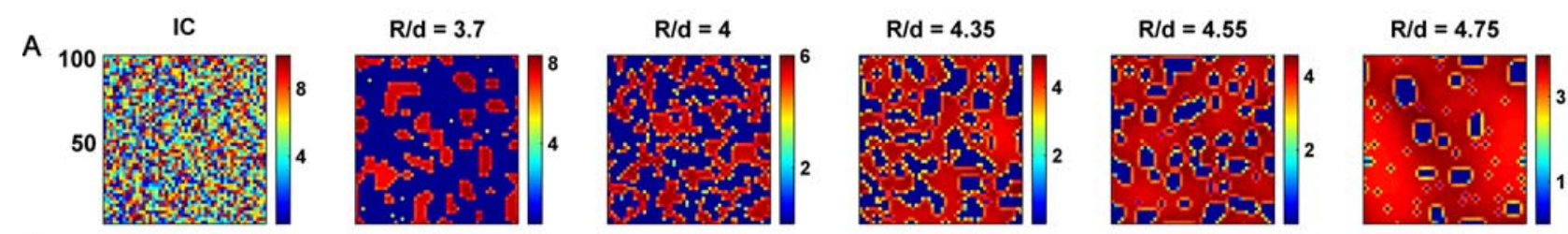

B
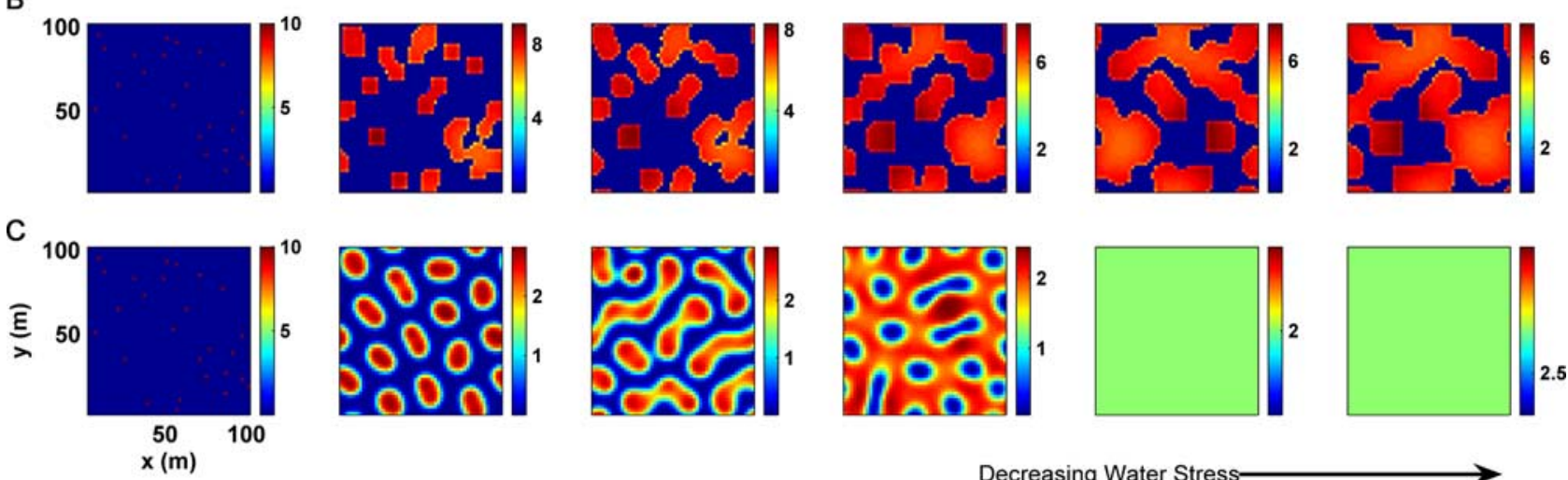

Figure 2. Simulation results of dimensionless biomass along a gradient of decreasing water stress for (a) the dispersion model with random initial conditions, (b) the dispersion model with random point initial conditions, and (c) the original diffusion model. The initial condition (IC) for each set of models is given. Length scales are shown on the left and the colors indicate the dimensionless biomass density (nondimensionalized by the biomass saturation constant for water infiltration). Increasing $R / d$ (rainfall to death rate) decreases soil moisture stress on growth. Note that the color scale differs between plots. The parameter values used were $c=10, g_{\max }=0.05, k_{1}=5, D_{p}=0.1, \alpha=0.2, k_{2}=5, W_{o}=0.2, r_{w}=0.2, D_{w}=$ $0.1, D_{o}=100, R=1$.

of a dispersion kernel and standing biomass, defining the seed rain about a parent plant [Thompson and Katul, 2008]. This adjustment to the biomass equation removes the dependence of the spatial movement on biomass gradients and allows for a variable length scale for dispersal, giving

$$
\begin{aligned}
\frac{\partial P}{\partial t}= & \left(c g_{\max } \frac{W}{W+k_{1}} P-d P\right)(1-\phi) \\
& +\phi\left(\iint \vartheta\left(x-x^{\prime}, y-y^{\prime}\right) P\left(x^{\prime}, y^{\prime}\right) d x^{\prime} d y^{\prime}\right),
\end{aligned}
$$

where $\vartheta$ is the dispersal kernel (that can account for secondary dispersal mechanisms if known), $\phi$ represents the proportion of standing biomass dispersed per unit time, $x^{\prime}$ and $y^{\prime}$ define the distance seeds move from the parent, integrated over the domain.

[12] Determining $\phi$ is problematic, as fecundity values vary strikingly between individuals and species, may change with environmental conditions, and are not typically reported as a percentage of biomass. The proportion of biomass that is allocated to reproduction can be as much as $50 \%$ for annuals, but is far less for many species [Aronson et al., 1993]. Determining the duration over which dispersal occurs complicates the conversion of this allocation to a rate. Assuming that the period during which a plant disperses seed ranges from 1 month to 1 year, and that $1-50 \%$ of the standing biomass is allocated to seed, then $\phi$ can be considered to range from $10^{-4}-10^{-2}$ day $^{-1}$. A plausible value in this range, $2.5 \times 10^{-3}$, was used for numerical simulations.
[13] A number of process- and timescale-related limitations apply to the model. Many of these have been addressed explicitly in other studies [see, e.g., Ursino, 2005, 2007; Ursino and Contarini, 2006] and are also discussed in Appendix A. The most significant concern is that representing the dynamics of a highly stochastic system using a deterministic model may misrepresent the system's drivers. This concern was addressed by linearizing the model equations at steady state and showing that the mean rainfall predicts the temporally averaged biomass response under stochastic rainfall conditions. This result is subject to limitations, as sporadic rainfall can annihilate the vegetation patterns and render further predictions or inference moot, but justifies the use of mean rainfall as a driver for this simple model at the timescales on which biomass changes. Details of the linearization are available in Appendix A. Other studies addressing the question of stochasticity and its relationship to patterning have concluded that stochastic rainfall may be a driver of pattern formation [D'Odorico et al., 2006b, 2007] and that while stochasticity changes the type of pattern formed for a given mean rainfall, it does not influence the overall shape of the patterns [Ursino and Contarini, 2006]. Finally, the hydrological processes represented in the model are also simplistic and based upon diffusion. Improvement of process representation in the hydrology and their integrated effects to timescales commensurate with biomass changes is an outstanding problem in this research field. 
Table 1. Details of Numerical Simulations and the Scientific Questions Addressed ${ }^{\mathrm{a}}$

\begin{tabular}{|c|c|c|c|}
\hline Research Question & Kernel & Initial Conditions & Parameter Notes \\
\hline $\begin{array}{l}\text { Where does small-scale disorder come } \\
\text { from? (Question 1) }\end{array}$ & $\begin{array}{l}\text { diffusion } \\
\text { and square } \\
\text { wave }\end{array}$ & $\begin{array}{l}\text { binary filter of } \\
\text { remote sensed } \\
\text { image }\end{array}$ & $\begin{array}{l}\frac{R}{d}=4.4 \mathrm{~mm} ; \text { diffusion coefficient }=0.01 ; \text { one } \\
\text { run with } k_{2} \text { parameter randomized }=5 \pm 0.5\end{array}$ \\
\hline $\begin{array}{l}\text { Can patterns be maintained without } \\
\text { diffusion? (Question 2a) }\end{array}$ & square wave & $\begin{array}{l}\text { point and } \\
\text { randomized }\end{array}$ & death rate $(d)=0.17-0.27$ day $^{-1}$ \\
\hline $\begin{array}{l}\text { What is the influence of initial } \\
\text { conditions on pattern formation? } \\
\text { (Question 2b) }\end{array}$ & square wave & $\begin{array}{l}\text { point and } \\
\quad \text { randomized }\end{array}$ & death rate $(d)=0.17-0.27$ day $^{-1}$ \\
\hline $\begin{array}{l}\text { Does a dispersion kernel model admit } \\
\text { bifurcations? (Question 3) }\end{array}$ & square wave & $\begin{array}{l}\text { point and } \\
\text { randomized }\end{array}$ & $\begin{array}{l}\text { allocation to dispersal }(\phi)=10^{-4}-0.3 \text { day }^{-1} \\
\quad \text { death rate }(d)=0.17-0.27 \text { day }^{-1}\end{array}$ \\
\hline $\begin{array}{l}\text { What is the impact of dispersal length } \\
\text { scales on patterns? (Question 4) }\end{array}$ & Wald & randomized & Wald variance $\sigma^{2}=0.5-32 \mathrm{~m}$; death rate $(d)=0.17-0.27$ day $^{-1}$ \\
\hline
\end{tabular}

${ }^{\mathrm{a}}$ The parameter values used for all simulations were $c=10, g_{\max }=0.05, k_{1}=5, D_{p}=0.1, \dot{a}=0.2, k_{2}=5, W_{o}=0.2, r_{w}=0.2 ; D_{w}=0.1, D_{o}=100, R=1$.

\subsection{Dispersion Kernels}

[14] A Wald kernel, defined by a Wald or Inverse Gaussian distribution was used for the simulations here. The kernel is given in radial coordinates by:

$$
\vartheta_{\text {Wald }}=\frac{1}{4 \pi d r} \sqrt{\left(\frac{\lambda}{2 \pi\left(r-r^{\prime}\right)^{3}}\right)} \exp \left\{\frac{-\lambda\left(\left(r-r^{\prime}\right)-\mu\right)^{2}}{2 \mu^{2}\left(r-r^{\prime}\right)}\right\},
$$

where $\mu>0$ is the mean of the distribution, $\lambda>0$ is a scale parameter, $r=\sqrt{x^{2}+y^{2}}, d r=\sqrt{d x^{2}+d y^{2}}$ and $r^{\prime}=$ $\sqrt{x^{\prime 2}+y^{\prime 2}}$. The variance of this distribution is given by $\sigma^{2}=\frac{\mu^{3}}{\lambda}$.

[15] The Wald kernel can be used to represent any dispersion length scale. In the local limit, it approximates a ballistic spread of seed about the parent and replicates the scale and spatial pattern of a Laplacian (i.e., the spatial term responsible for diffusion). In the nonlocal limit, the kernel allows for wind-dispersed seeds to travel long distances [Katul et al., 2005].

\subsection{Numerical Simulations and Methods of Analysis}

[16] The numerical simulations performed are summarized in Table 1 . All simulations were run on a $100 \times 100 \mathrm{~m}$ grid with $2 \times 2 \mathrm{~m}$ cells and periodic boundary conditions with a timestep of $0.008 \mathrm{~d}$. Simulations initialized with a remote sensing image were run on a $550 \times 700 \mathrm{~m}$ grid with $2.8 \times 2.8 \mathrm{~m}$ cells. Numerical calculations were performed using an Euler forward difference scheme, and the convolution between the biomass and the dispersal kernel was performed in the Fourier domain using a fast Fourier transform algorithm for two-dimensional convolutions (L. Rosa, CONV2FFT, computer code, edited by M. C. F. Exchange, 2004, available at http://www.mathworks.com/matlabcentral/ fileexchange/loadCategory.do). Simulations were run until the steady state biomass was reached, typically 2000 days (determined as the point where the rate of change in biomass, normalized by the standing biomass, was less than $1 \times 10^{-4}$ ). Unless shown otherwise in Table 1 , all model parameters are those used by Rietkerk et al. [2002]. Table 1 shows five different model runs, addressing the 4 key research questions outlined in the introduction (and elaborated upon next), as well as important tests of model validity, specifically with respect to identifying bifurcations in model behavior. The methodological details are below.

\subsection{Question 1: Does Small-Scale Disorder in Vegetation Patterns Arise From Extrinsic Randomness or Intrinsic Processes?}

[17] To address this question, three cases were considered: a basic diffusion model, the kernel model using a square wave kernel, and the diffusion model running on a grid where the soil parameter $\mathrm{k}_{2}$ (the half saturation constant for the infiltration rate) was treated as an uncorrelated Gaussian random field varying by $10 \%$ around its mean. Extensive studies into the nature and scaling of soil heterogeneity support the notion that variability in soil properties is uncorrelated on scales of $1-100 \mathrm{~m}$, those relevant to this model, and thus support the treatment of small-scale randomness as uncorrelated in space [Buchter et al., 1991]. To remove uncertainty regarding the initial conditions, the models were initialized with an image taken from remote sensing and passed through a binary filter. Runs were initialized by holding the biomass constant in time until the water terms reached steady state. Biomass was then allowed to adjust to this new soil moisture spatial distribution. This approach avoided creating transient artifacts that might disrupt the initial biomass conditions while the water terms equilibrated. The model was run with different rainfall values until an optimal approximation of the original biomass pattern was reached (tested by the absolute difference and RMS difference between steady state results and the initial condition). A water availability measure of $\frac{R}{d}=$ $4.4 \mathrm{~mm}$ was adopted for all simulations. Power spectra of the steady state solutions were calculated using a twodimensional Fourier transform. For clarity, the most energetic modes, normalized by the area under the spectrum, were plotted against wavelength.

\subsection{Question 2: Can Vegetation Patterns Be Generated Without Treating Vegetation Transport as Diffusion? What Are the Influences of the Initial Conditions?}

[18] These questions were addressed in concert by running comparisons of the original diffusion model and the square wave kernel based model across a gradient of water stress for different initial conditions and comparing the results. The initial conditions used consisted first of a perturbation about continuous biomass cover in the range of $0-50 \mathrm{~g} \mathrm{~m}^{-2}$ ("random" initial conditions), broadly analogous to a drying climate fragmenting initially continuous vegetation cover. Other ranges of variability in the random initial condition were also tested. The second initial 

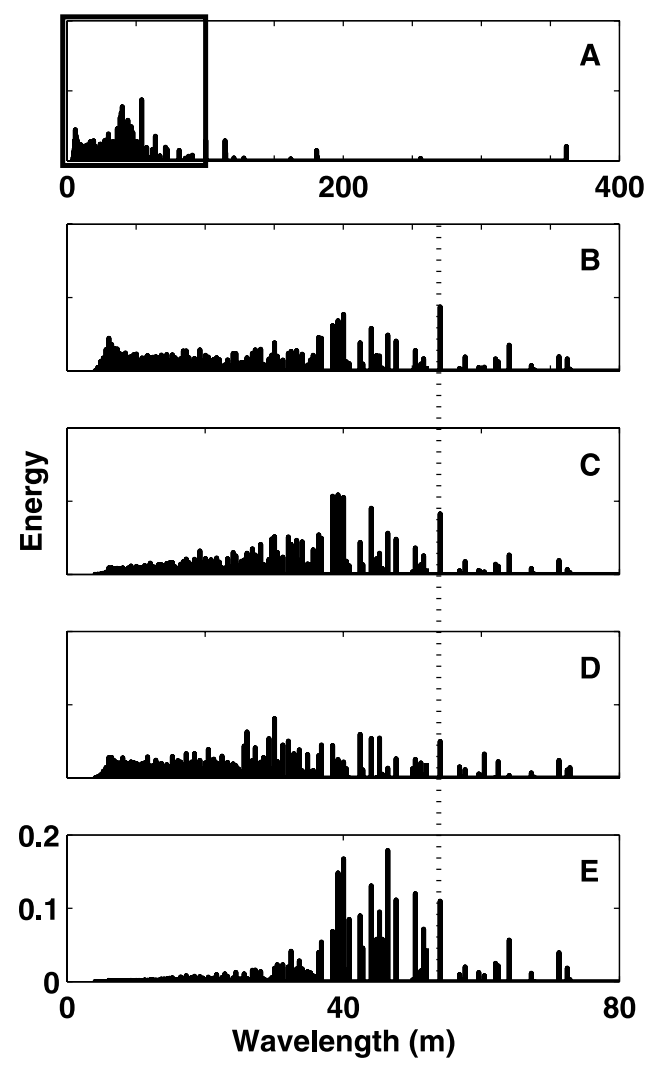

Figure 3. Comparison of measured and modeled power spectra, represented here by a scalar wavelength. The spectra are normalized by their respective areas. (a) The full spectrum obtained from the remote sensing image (Figure 1a). (b) Magnification of area indicated by insert in Figure 3a. (c) The spectrum from the dispersion model for the same range in wavelengths. (d) The analogous spectrum arising from the diffusion model runs with stochastic soil properties. (e) The spectrum from a diffusion model assuming homogeneous soil/vegetation parameters in space. The dotted vertical line indicates the most energetic length scale observed from the Google Earth image.

condition used was a random seeding of an otherwise unvegetated landscape $5 \%$ of cells initiated at a biomass density of $50 \mathrm{~g} \mathrm{~m}^{-2}$, other cells at $0 \mathrm{~g} \mathrm{~m}^{-2}$, "point" initial conditions), broadly analogous to the revegetation of a desertified region via random germination from a seedbank or randomly dispersed individual seeds. The initial conditions are shown as the leftmost column in Figure 2.

\subsection{Question 3: Does the Kernel-Based Model Admit Bifurcations?}

[19] The possibility of bifurcations existing in the new model was explored by changing the dispersion allocation parameter $\phi$ over the biologically realistic range for varying values of plant stress.

\subsection{Question 4: What Is the Impact of the Dispersion} Length Scale on the Biomass Steady State?

[20] The dependence of the steady state biomass characteristics on the length scale of dispersal was evaluated by varying the plant stress term and the dispersal length scales concurrently. Dispersal length scales were varied from 0.5 to $32 \mathrm{~m}$, encompassing scales both smaller and greater than the typical length scales of vegetation patterns. The characteristics of the biomass were evaluated in terms of the total standing biomass at steady state (nondimensionalized by $k_{2}$ ) and the site occupancy, expressed as a percentage of the domain size. A site was defined as occupied if the scaled biomass density $\left(P / k_{2}\right)>1$. This threshold was set to exceed the biomass density within "bare patches" and to encapsulate all biomass within "occupied" patches over all simulations. Trends in the characteristic length scales of the patterns as evaluated from power spectra, and in the amplitude of the patterning were also recorded.

\section{Results and Discussion}

[21] From the simulations in Table 1, the results are presented thematically following the questions outlined previously. It should be emphasized here that the simulation results are generic and are not intended to represent a particular ecosystem.

\subsection{Question 1: Does Small-Scale Disorder in Vegetation Patterns Arise From Extrinsic Randomness or Intrinsic Processes?}

[22] Initiating the model with a vegetation pattern taken from a remote sensing image allows an evaluation of the model's capability to preserve real features of patterned vegetation, and permits a direct comparison of the fine-scale features of different model results in terms of two dimensional power spectra. Encouragingly, for appropriate choices of the rainfall/mortality forcing, the models used preserved many of the spatial features of the initial condition. A comparison of the patterns generated by the diffusion model, a diffusion model with random soil properties, and a dispersion model showed that the dispersion model best preserved the energetic length scales found in field data (Figure $3 \mathrm{~b}$ and $3 \mathrm{c}$ ). A comparison of the power spectra of these cases showed good correspondence between the remotely sensed image and the dispersion model. The addition of random soil properties through randomization of the $k_{2}$ term generated new energetic length scales and spread the energy out over this range, reducing the distinctiveness of the pattern (Figure 3c), while the diffusion model alone constrained the range of energetic length scales (Figure 3d). Preservation of the energetic length scales of real data is a necessary but not sufficient condition upon which to evaluate the model's performance; these results provide encouraging but not conclusive support for the use of the kernel-based model.

\subsection{Question 2a: Can Patterns Be Maintained in the Absence of Diffusion?}

[23] The model results indicate that pattern formation can persist without requiring biomass to diffuse. This is an important confirmation that the proposed mechanisms for pattern formation, which until now have been demonstrated only with idealized descriptions of vegetation transport, are compatible with realistic vegetation movement processes. The results obtained via a dispersal kernel contrast to those obtained from previous kernel and diffusion based models by increasing the steady state biomass density and decreasing the regularity of the steady state biomass patterns. Despite differences in pattern appearance, the disordered 
patterns generated by the dispersion model recapitulated the trends with water stress seen in the diffusion model. Linear stability analysis supported the interpretation that dispersion destabilized the pattern formation properties of the model, as the range of unstable wavelengths increased markedly [Murray, 2002] (see also Appendix A). The outcomes from using kernels in pattern-forming models depend on the shape and purpose of the kernel. Lefever and Lejeune [1997] use a kernel to encode the feedbacks that result in pattern formation to generate smooth, regular patterns. By contrast, our kernel purely results in transport of biomass and has the effect of removing sensitivity of that transport to biomass gradients, a sensitivity that was maintained in the Lejeune and Lefever model. The kernel in this model is independent of biomass gradients. It is thus less diffusive and admits disordered solutions that diffusion would tend to smooth out. In fact, some of the patterns generated by the dispersion model appear less regular than those observed in nature, raising the possibility that biomass movement might preserve some diffusive features. A potential source of such behavior might lie in vegetative reproduction (through clonal growth), which is known to occur in several of the species that form patterned vegetation (e.g., Combretum micranthum, Guiera senegalensis, Pleuraphis (formerly Hilaria) murtica) [Couteron and Lejeune, 2001]. The prevalence of vegetative versus sexual reproduction, however, is not clear [Thiombiano et al., 2003; R. Uchytil, Pleuraphis mutica, in Fire Effects Information System, Fire Sciences Laboratory, Rocky Mountain Research Station, Forest Service, U.S. Department of Agriculture, 1988, available at http://www.fs.fed.us/database/feis/plants/graminoid/plemut/ all.html]. Another possible explanation for the model's less regular patterns is that the coupling in time between rainfall and seed production or dispersal, as is common in arid ecosystem [Ellner and Shmida, 1981], may act to smooth patterns by subsuming smaller scales during periods of vegetation expansion or consuming them during periods of water stress. These two effects do "smooth out" biomass fronts.

\subsection{Question 2b: What Is the Influence of Initial Conditions on Pattern Formation?}

[24] The dependence on ICs between the diffusion model and the kernel-based model was quite different. The final pattern form was largely independent of the ICs in the diffusion model, but was highly sensitive to ICs in the dispersion case, shifting from a "frozen" state generated by point ICs where biomass expanded about the initial points until the expansion was halted by water depletion at the boundary of the vegetation patches, as in Figure $2 b$, to the "disordered" patterns generated from random ICs, as in Figure 2a. The sensitivity of the final pattern to the degree of randomness imposed in the random initial condition was also tested. The patterns displayed less disorder as the magnitude of the initial disturbance declined, but remained highly disordered in comparison to a diffusion model (see auxiliary material for details). ${ }^{1}$

[25] This dramatic change in spatial organization and sensitivity to initial conditions in contrast to diffusion-based models can be understood as a combination of two factors:

\footnotetext{
${ }^{1}$ Auxiliary materials are available in the HTML. doi:10.1029/ 2008WR006916.
}

the stabilization of sharp biomass fronts, and the importance of connectivity between vegetation patches in moderating the plant-water spatial dynamics. While diffusion acts to erode sharp biomass fronts, these fronts remain stable in the kernel-based model, and are susceptible to being "pinned" by equally abrupt water limitation at the expanding edge, preventing the growth and establishment of dispersed seed ahead of the front. Under such circumstances, isolated patches expand outward symmetrically until the growth is halted by water limitation. These patches do not fragment but remain cohesive within the pinned boundary, generating the "frozen state." When the model is initiated with continuous vegetation cover, the vegetation patterning is not driven by the expansion and pinning of patches but by the disintegration of the initial vegetation cover due to the surface water dynamics. The point initiation case can be viewed as being driven by the expansion of the biomass, and the random initial conditions case by the reallocation of soil moisture, with different results for the ultimate spatial organization. The unrealistic form of the patterns generated by the point diffusion case suggests that vegetation patterns are unlikely to have resulted from colonization of sites by dispersed seed, and lends support to the possibility that patterns originate from the fragmentation of homogeneous vegetation cover under increasing water stress.

\subsection{Question 3: Does the Dispersion Kernel Model Admit Bifurcations?}

[26] Bifurcations between disordered patterns, ordered patterns, and homogeneous vegetation occurred with changes in $\phi$, however these were located at values of $\phi>$ $1 \times 10^{-2}$, outside the biologically realistic range of $\phi(1 \times$ $10^{-4}-1 \times 10^{-2}$ day $\left.^{-1}\right)$. Realistic $\phi$ values generated disordered patterns or homogeneous biomass (see auxiliary material for bifurcation diagram). These results provide confidence that the variations observed in the dispersion model output were independent of the choice of $\phi$.

\subsection{Question 4: What Is the Impact of Dispersal Length Scale on Observed Patterns?}

[27] Trends in spatial organization, biomass, occupancy $\left(P / k_{2}>1\right)$, pattern amplitude and pattern length scale were evident with changing dispersion length scales and water stress. Trends in pattern length scale and amplitude appeared to be specific to the pattern type. Length scales of gaps (i.e., bare sites) and spots (i.e., vegetated sites) declined as the dispersion length increased, while the length scales of labyrinthine patterns were largely unchanged. The trends in amplitude reflected the trends in length scale, with biomass generally increasing as vegetation cover declined. Overall the magnitude of these changes was on the order of $10-15 \%$ while dispersal length changed over 2 orders of magnitude. Despite the trends, it was difficult to identify any signal of changing dispersion length in power spectra of the patterns. This is rather encouraging from the perspective of inverse modeling, as it suggests that the dispersal length parameter, which is difficult to estimate a priori, will have only a minimal influence on the remainder of the pattern form.

[28] The impact of the trends in total biomass and site occupancy was evaluated using an index that combined the total biomass and the degree of site occupancy by multiplying the standing biomass (normalized by the maximum 

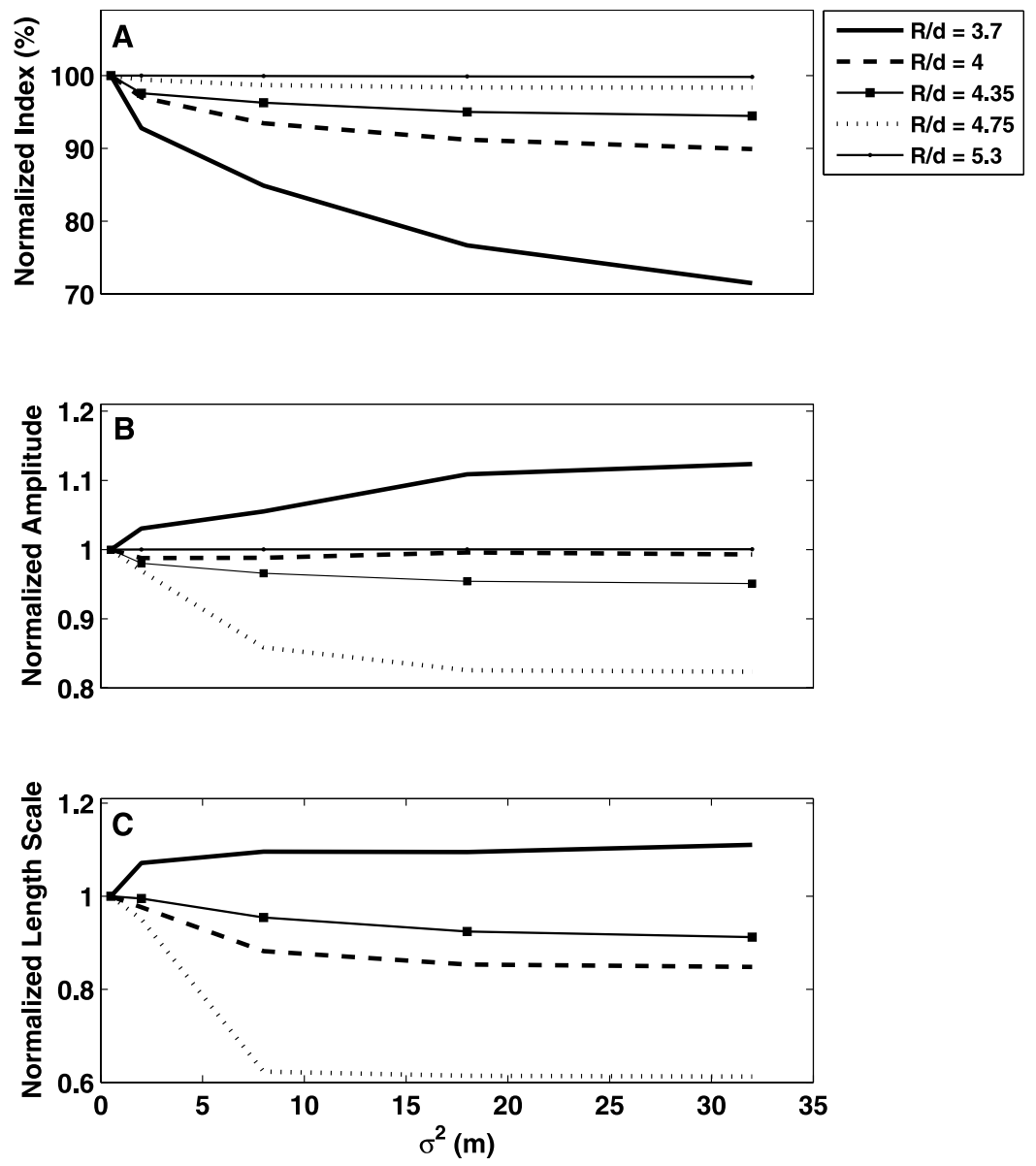

Figure 4. Variations in pattern properties with changing length scales of seed dispersal. (a) Changes in the combined biomass/occupancy index for random initial conditions. (b) Trends in the amplitude of the patterns, with the amplitude shown normalized against the $\sigma^{2}=0.5$ case. (c) Changes in the characteristic length scale (as interpreted from power spectra) of the patterns, with the length scale shown normalized against the $\sigma^{2}=0.5$ case. Increasing $R / d$ indicates decreasing water stress.

standing biomass achieved under the environmental conditions) by the percentage of occupied cells, and normalizing again by the highest value of this index for each set of environmental conditions tested. Trends in the index (Figure 4a), as well as for the amplitude (Figure 4b) and pattern length scale (Figure 4c), are shown in Figure 4 for the random initial conditions case. The index decreased with increased dispersion distance, with the greatest decreases associated with the highest water stress and approaching zero as the water stress was reduced.

[29] The use of a simple multiplicative index to capture the variations in standing biomass and its distribution was based upon a simplified assumption that plants in general should seek to maximize both their standing biomass and their extent. This assumption neglects the subtleties of real ecological responses and should be treated with caution: nonetheless the trends found are intriguing and suggest that there may indeed be a feedback between the pattern formation in these systems and dispersal strategy selection. The trends furthermore agree with empirical evidence of a preponderance of anti telechory and atelechory (localized dispersal) in desert ecosystems, and suggest that there may be a link between water availability and seed dispersal length scales. Within the model framework, the decline in the index with dispersal length can be attributed to the increased probability of seeds being dispersed to regions with an impoverished soil moisture resource as the dispersal length increases. At short dispersal distances a greater proportion of seeds germinate in a region of relatively high water availability near the parent. We note that although we did not explicitly incorporate the inhibition of seedling germination over crusted soils into this model, that this would be a further feedback enhancing plant success when seed dispersal preferentially routed seeds to vegetated sites. This might also lead to more regular vegetation patterns (see above).

[30] This simple description is intriguing, and while obviously limited by lack of explicit consideration of genetics, intergenerational competition and other factors needed to evaluate optimal reproductive strategies for plants, it indicates that the links between plant dispersal strategies, organizing features in the environment, and other edaphic drivers deserves more detailed theoretical treatment.

\section{Conclusions}

[31] While extensive effort has been invested in understanding the nonlinear interactions between plants and water in pattern-forming vegetation within the last decade or so, 


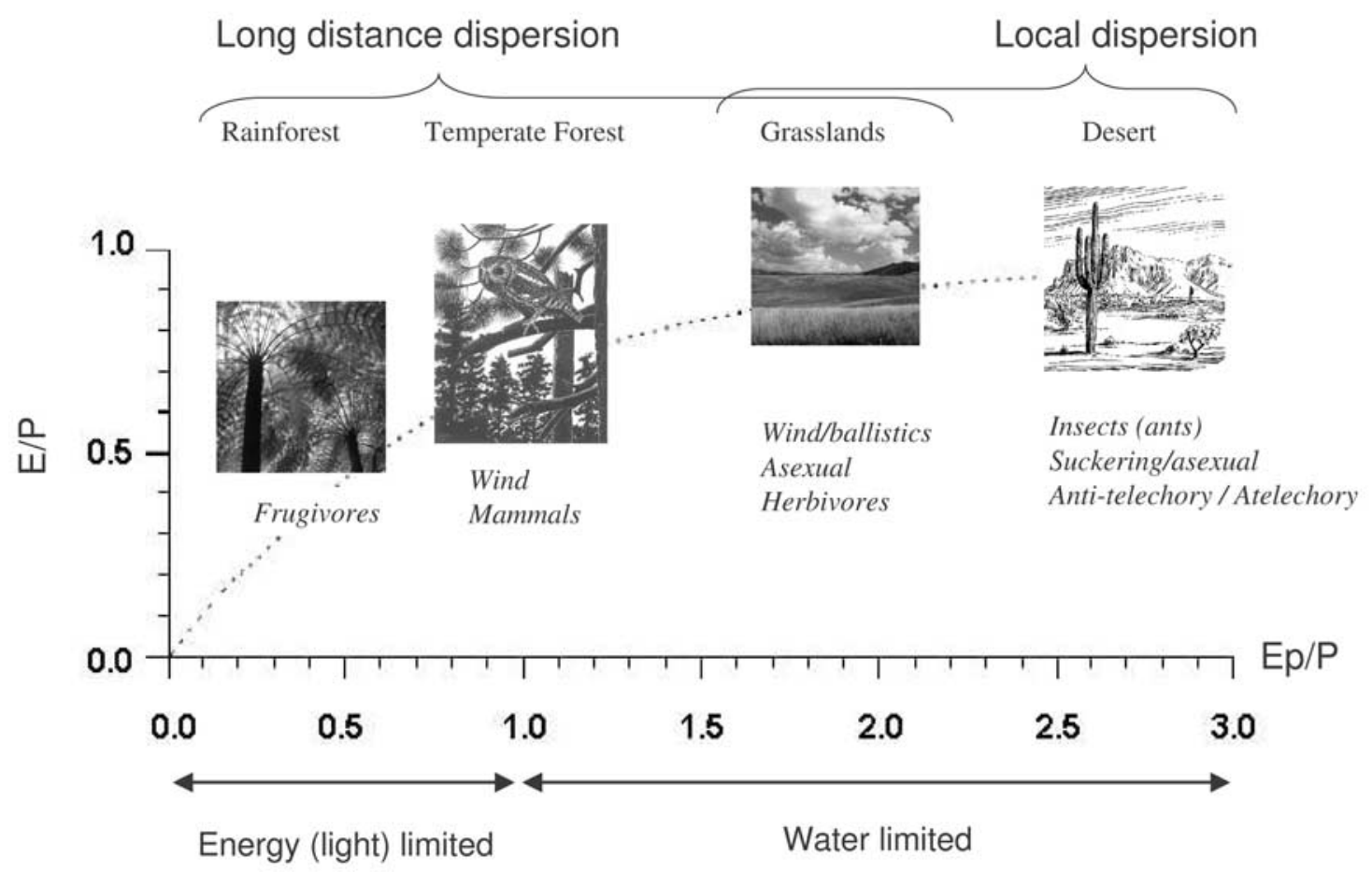

Figure 5. Trends in dispersal length and strategy broadly vary along the Budyko Curve. The abscissa value, Budyko's "radiative index of dryness" represents the ratio of potential evapotranspiration to precipitation, and as such is a measure of water limitation $(E p / P>1$, i.e., more water can be removed from the landscape via evapotranspiration than is delivered to it) or energy limitation $(E p / P<1$, i.e., more water is delivered to the landscape than evapotranspiration can remove). The ordinate value is the ratio of actual evaporation to precipitation.

the role of vegetation transport has been less studied. It appears, however, that the description of spatial movement of the plant population has the capacity to significantly alter the steady state spatial patterns in these systems, through changing sensitivity to initial conditions and destabilizing the patterns formed over a wider range of length scales. Indeed, the increased range of length scales may result in improved representations of steady state biomass, on the basis of a comparison with measured spatial power spectra of vegetation density. These results suggest that spatial heterogeneity, for example in soil properties, need not be the source of disorder in vegetation patterns, but that the decoupling between biomass gradients and dispersion terms may also act to introduce a broader spectrum of length scales of variability. To further evaluate this hypothesis, studies of the dispersal ecology of pattern forming species are needed, to quantify modes of reproduction (sexual versus asexual), length scales of dispersal and the relationship between soil moisture availability and seedling success and survival. In an environment limited by the soil water resource, such studies may allow the separation of the roles of biomass movement and water supply as the processes determining patterns of spatial organization.

\section{Further Implications}

[32] The apparent interaction of water availability and dispersal length scales in determining steady state biomass parameters remains intriguing and warrants further investigation. In particular, it raises the question of whether environmental controls upon dispersal behavior can be identified more generally across ecosystem types. Studies of the interaction between dispersal strategy and environment at the ecosystem level suggest that factors such as climate and disturbance play important roles in selecting dispersal mechanisms [Ellner and Shmida, 1981; Reichman, 1984; Abrams, 1988; Fragoso, 1997; Clauss and Venable, 2000; Fragoso et al., 2003], while broad trends can be identified between ecosystems. To view such trends through an ecohydrological lens, the classical Budyko Curve [Budyko, 1974] provides a tantalizing starting point toward a conceptual framework (Figure 5). A survey of typical modes of dispersal across biomes suggests that there is a predominance of short-range dispersal in arid ecosystems, longer-range wind- and animal-driven dispersal in grasslands and temperate ecosystems, and long-range animal dispersal (with little wind dispersal) in tropical ecosystems [Howe and Smallwood, 1982; Chambers and MacMahon, 1994]. The findings in this study suggest that it may be possible to quantify the linkage between an edaphic forcing term (such as precipitation) and dispersal optimization in arid ecosystems. We speculate that, given the control of hydraulics on plant height, resource availability on canopy densities, and energy inputs on disturbance, it may be possible to establish a general framework relating optimal 
ecosystem dispersion strategies to the processes, patterns, and organizing principles that drive their physical environments.

\section{Appendix A}

[33] Appendix A provides further detail regarding the model limitations, the shape of the dispersion kernels, and interpretation of the linear stability analysis and derivation of the dispersion relation.

\section{A1. Model Limitations: Process and Timescale Considerations}

[34] The model used is a simplified description of the biology, ecology and hydrology of water-limited ecosystems. Given the essentially "infinite" complexity of a real system, a critique of such a simple model can be carried on indefinitely. We confine this critique to the most salient limitations of the ecohydrological model, which essentially amount to limitations in the process descriptions adopted, and the consequences of a deterministic representation of truly stochastic drivers, particularly rainfall.

[35] The plant physiology is simplified, treating growth as a function of water availability only (a reasonable but inexact approximation in arid ecosystems because of the instantaneous linkages between photosynthesis and water availability); and all parameters are treated as constant in space and time, generating results representing mean responses over long timescales. The hydrology represented in the model is also primitive, relying upon a representation of both surface and soil water movement as diffusion. These representations are not strictly realistic, but given that infiltration and plant uptake are of interest rather than the precise routing of the flow to the plant, the simple representation is perhaps suitable at the biomass timescale.

[36] The model is continuous in space and time, and represents deterministic processes dependent upon the mean environmental conditions. As such it omits temporal variability, and cannot represent the stochastic nature of many important processes in arid ecosystem (e.g., rainfall). This approach, however, captures the trends at long timescales, and allows an evaluation of their effects in isolation from transient processes, which given the large separation of timescales between the surface water transport and the biomass response is reasonable. Furthermore, adopting a quasi-steady state approximation and linearizing the equations, the time averaged biomass response can be predicted by the time averaged rainfall (see Linearization of the surface water terms, below).

\section{A2. Linearization of the Surface Water Term}

[37] The scale separation between the surface water response time and the biomass/soil water response time in the ecohydrological model can be evaluated in the diffusive framework by the ratio of $D_{o}: D_{p}(1000)$, and in the dispersive framework by $\frac{D_{o}}{\phi \sigma(\vartheta)}$, where $\sigma(\vartheta)$ is the standard deviation of the dispersal kernel. Taking an upper limit of $\sigma(\vartheta)=100$, the ratio can then be evaluated as: $\frac{100}{0.25}$ or $\sim 400$. This large-scale separation suggests that at steady state, changes in the surface water terms occur so rapidly in comparison to the biomass and soil moisture terms, as to allow the surface water to be approximated as stationary during biomass growth.
[38] The linearized equations are time averaged from the fast scales of overland flow (minutes) to the slower timescales of biomass response (annual), with the aim of investigating how fluctuations in rainfall about the mean are propagated into the biomass evolution equation, and under what conditions it is reasonable to approximate the temporally variable rainfall by its long-term mean state for arriving at stationary patterns.

[39] Consider the model equations, reproduced here for convenience, at steady state. In this case, the rapid response of the surface water allows the approximation $\frac{\partial O}{\partial t}=0$ to be made

$$
\frac{\partial P}{\partial t}=c g_{\max } \frac{W}{W+k_{1}} P-d P+D_{p} \Delta P
$$

where $P$ is the plant biomass in $\mathrm{g} \mathrm{m}^{-2}$;

$$
\frac{\partial W}{\partial t}=\alpha O \frac{P+k_{2} W_{o}}{P+k_{2}}-g_{\max } \frac{W}{W+k_{1}} P-r_{w} W+D_{w} \Delta W,
$$

where $W$ is the soil water depth in $\mathrm{mm}$; and

$$
0=R-\alpha O \frac{P+k_{2} W_{o}}{P+k_{2}}+D_{o} \Delta O
$$

where $O$ is the surface water in $\mathrm{mm}$. That is,

$$
O=\frac{1}{\alpha}\left(R+D_{o} \Delta O\right)\left(\frac{P+k_{2}}{P+k_{2} W_{o}}\right)
$$

Hence, at steady state, changes in biomass occur much more slowly than changes in the surface water budget, and the multiplier can be considered to be constant, $\kappa$ so that $O$ is linearly forced by rainfall

$$
O=\frac{1}{\alpha}\left(R+D_{o} \Delta O\right) \kappa
$$

Substituting (A1) into the steady state $W$ equation allows the simplification

$$
\frac{\partial W}{\partial t}=\left(R+D_{o} \Delta O\right)-g_{\max } \frac{W}{W+k_{1}} P-r_{w} W+D_{w} \Delta W,
$$

suggesting that the response of $W$ to rainfall forcing is also linear.

[40] This approach removes one of the key nonlinearities but a further linearization step is necessary to treat the plant water uptake term $\frac{W}{W+k_{1}} P$. Performing Reynolds decomposition on this term yields

$$
\frac{\bar{W}+W^{\prime}}{\bar{W}+W^{\prime}+k_{1}}\left(\bar{P}+P^{\prime}\right)
$$

where primed quantities are excursions from the temporal average indicated by an over bar. When the fluctuations in soil moisture are small by comparison to $k_{1}$ (a reasonable assumption as the maximum steady state soil moisture is 

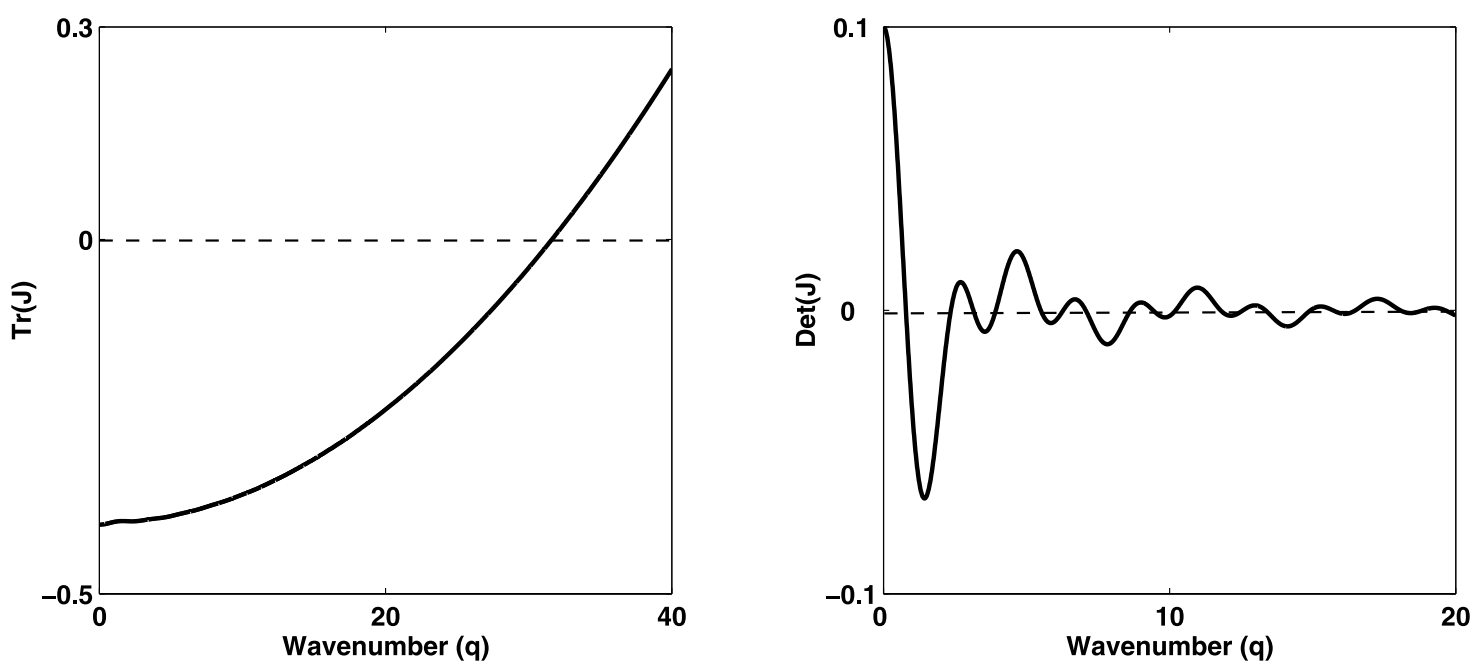

Figure A1. Plot of the (a) trace and (b) determinant of the Jacobian matrix describing the growth of perturbations about the bare soil steady state. By comparison to a constant value of the trace and a single sign change in the determinant with positive wave numbers obtained for the diffusion situation, the use of the dispersion equation introduces a sign change into the description of the trace and "spreads" the instability over a wide range of wave numbers because of the fluctuations in the determinant.

typically on the order of $k_{1}$ ), and upon time averaging this term, we obtain

$$
\begin{aligned}
\overline{\left(\frac{W}{W+k_{1}} P\right)} & \approx \frac{\overline{W P}}{\bar{W}+k_{1}}\left(1+\frac{\overline{W^{\prime} P^{\prime}}}{\overline{W P}}\right) \\
& =\frac{\overline{W P}}{\bar{W}+k_{1}}\left(1+R_{w, p} \frac{\sigma_{w}}{\bar{W}} \frac{\sigma_{p}}{\bar{P}}\right),
\end{aligned}
$$

where $\sigma$ is the standard deviation, and $R_{w, p} \in[0,1]$ is the correlation coefficient between rainfall and soil moisture variability (positive in this case). Hence, a necessary condition for using only mean annual rainfall in biomass models is that

$$
R_{w, p} \frac{\sigma_{w}}{\bar{W}} \frac{\sigma_{p}}{\bar{P}}<<1
$$

Given that $R_{w, p} \sim 1$ in arid ecosystems, the condition above is reasonable if the coefficients of variation in rainfall and soil moisture do not exceed $30 \%$ each.

\section{A3. Linear Stability Analysis and the Dispersion Relation}

[41] The analysis follows the methods used by HilleRisLambers et al. [2001] and is not reproduced in full here. The pertinent steps may be summarized as (1) nondimensionalize the model equations; (2) recognize that the timescales of surface water transport are $10^{3}$ times greater than biomass or soil water response, thus at long timescales a pseudosteady state approximation can be applied (i.e., $\frac{\partial O}{\partial t}=0$ ); (3) determine the steady state solution(s) and apply a periodic perturbation; (4) by the pseudosteady state approximation, the growth in the perturbation of the surface water can also be taken as zero; and (5) use this approach to contract the system of three equations to two ODES describing the growth of the perturbations in the soil and biomass terms.
[42] We evaluate the results for the particular case where $R=1$ and $d=0.23$. We do not reproduce the derivation of the results for the diffusive case, except to note that under these conditions, wave numbers of less than 31.6 are stable.

[43] Before proceeding further, two points must be noted: this procedure does not allow us to define the dispersion relation and so while it determines conditions for pattern formation, it does not identify the most rapidly growing modes; second most of the pattern formation that is important in this model arises because of nonlinear instabilities, and these results should be treated as indicative only of the impact of replacing a diffusive term with a dispersion term. In this analysis, we examine the case of the bare soil steady state. Performing a similar analysis at the vegetated state fails to reveal significant differences between the dispersion and diffusion approaches, again suggesting that the nonlinear instabilities are principally responsible for the changes in pattern behavior.

[44] In one dimension, perturbations in the biomass and soil water terms are given by

$$
\varepsilon(x, t)=\varepsilon(t) \cos (q x), \quad \psi(x, t)=\psi(t) \cos (q x),
$$

respectively. Here $q$ represents the wave number of the perturbations. Linearizing around the steady states by taking $P=P+\varepsilon(t)$ and $W=W+\psi(t)$ and using the pseudosteady state approximation, an expression for the growth of the perturbations is obtained

$$
\begin{aligned}
\frac{\partial \varepsilon}{\partial t}= & \phi \mathrm{FT}(q) \varepsilon(t)+\frac{P}{(W+1)^{2}} \psi(t) \\
\frac{\partial \psi(t)}{\partial t}= & \left(\frac{P}{(W+1)^{2}}-\frac{P+W_{o}}{P+1} \times \frac{\left(-O \frac{1-W_{o}}{P+1}\right)}{\left(-\frac{P+W_{o}}{P+1}-q^{2}\right)}\right) \varepsilon(t) \\
& +\left(-\left(\frac{k P}{(W+1)^{2}}+r\right)-D_{w} q^{2}\right) \psi(t)
\end{aligned}
$$


Here $\operatorname{FT}(q)$ represents the one-dimensional Fourier transform of the dispersion kernel. For the case where the kernel can be approximated by a square wave, the Fourier transform is

$$
\begin{aligned}
\operatorname{FT}(q)= & i e^{-i\left(c_{1}+c_{2}\right) q}\left(-e^{i c_{1} q}+e^{i c_{2} q}-e^{i\left(2 c_{1}+c_{2}\right) q}+e^{i\left(c_{1}+2 c_{2}\right) q}\right) \\
& \cdot \frac{H\left[c_{1}-c_{2}\right]}{2 q\left|c_{1}-c_{2}\right|}
\end{aligned}
$$

where $c_{1}$ and $c_{2}$ can be taken as $\frac{d x}{2}$ and $\frac{3 d x}{2}$, or 1 and 3 for the case modeled in this paper $(d o=2)$, and where $H$ represents the Heaviside function.

[45] The Jacobian for this system of equations can be found

$J=\left[\begin{array}{cc}-\phi \mathrm{FT}(q) & \frac{P}{(W+1)^{2}} \\ -b k+O \frac{\left(1-W_{o}\right)}{1+P}+O \frac{\left(1-W_{o}\right)}{(1+P)^{2}} \frac{\left(P+W_{o}\right)}{\left(q^{2}+\frac{P+W o}{1+P}\right)} & D_{w} q^{2}-r-\frac{k P}{(1+W)^{2}}\end{array}\right]$.

Conditions for the stability of the steady states in terms of the wave number $q$ can be determined on the basis of the typical conditions for stability

$$
\operatorname{Tr}(J)<0, \operatorname{Det}(J)>0,
$$

where

$$
\begin{aligned}
\operatorname{Tr}(J)= & -\phi \mathrm{FT}(q)+D_{w} q^{2}-r-\frac{k P}{(1+W)^{2}}, \\
\operatorname{Det}(J)= & -(-\varphi \mathrm{FT}(q))\left(D_{w} q^{2}-r-\frac{k P}{(1+W)^{2}}\right)- \\
& \cdot\left(-b k+O \frac{\left(1-W_{o}\right)}{1+P}+O \frac{\left(1-W_{o}\right)}{(1+P)^{2}} \frac{\left(P+W_{o}\right)}{\left(q^{2}+\frac{P+W_{o}}{1+P}\right)}\right) \\
& \cdot\left(\frac{P}{(W+1)^{2}}\right) .
\end{aligned}
$$

[46] Taking the no biomass steady state and the parameters used in this paper, we obtain

$$
\begin{aligned}
\operatorname{Tr}(J) & =-0.4+\frac{q^{2}}{2500}-2.5 \times 10^{-3} \mathrm{FT}(q), \\
\operatorname{Det}(J) & =0.01-2.5 \times 10^{-3} \mathrm{FT}(q)\left(-0.42+\frac{q^{2}}{2500}\right) .
\end{aligned}
$$

[47] Figure A1 shows that all wave numbers greater than 31.6 are again unstable, now because of the sign change in $\operatorname{Tr}(J)$, while additional wave numbers are introduced because of the oscillations of $\operatorname{Det}(J)$. This broadening of the range of linearly unstable wave numbers is indicative of a general destabilization of the model to spatially variable perturbations.

[48] Acknowledgments. S. Thompson acknowledges support from the General Sir John Monash Foundation and thanks A. Manor and N. Shnerb for their input and suggestions. G. Katul acknowledges support from the National Science Foundation (NSF-EAR 06-35787, NSF-EAR-0628432, and NSF-ATM-0724088), the Binational Agricultural Research and Development (BARD, Research grant IS3861-06), and the U.S. Department of Agriculture Biotechnology Risk Assessment Program (grant 200539454-16457). S. M. McMahon acknowledges support from the National Science Foundation (NSF-DEB-3331618).

\section{References}

Abrams, M. D. (1988), Effects of burning regime on buried seed banks and canopy coverage in a Kansas tallgrass prairie, Southwest. Nat., 33, 6570, doi: $10.2307 / 3672089$.

Aronson, J., J. Kigel, and A. Shmida (1993), Reproductive allocation strategies in desert and Mediterranean populations of annual plants grown with and without water-stress, Oecologia, 93, 336-342, doi:10.1007/BF00317875.

Belnap, J., B. Budel, and O. L. Lange (2001), Biological soil crusts: Characteristics and distribution, in Biological Soil Crusts: Structure, Function and Management, edited by J. Belnap and O. L. Lange, pp. 3-30, Springer, New York.

Briggs, G. E., and J. B. S. Haldane (1925), A note on the kinetics of enzyme action, Biochem. J., 19, 338-339.

Bromley, J., J. Brouwer, A. P. Barker, S. R. Gaze, and C. Valentin (1997), The role of surface water redistribution in an area of patterned vegetation in a semi-arid environment, south-west Niger, J. Hydrol. Amsterdam, 198, 1-29, doi:10.1016/S0022-1694(96)03322-7.

Buchter, B., P. O. Aina, A. S. Azari, and D. R. Nielsen (1991), Soil spatial variability along transects, Soil Technol., 4, 297-314, doi:10.1016/09333630(91)90008-B.

Budyko, M. I. (1974), Climate and Life, Academic, San Diego, Calif.

Cain, M. L., B. G. Milligan, and A. E. Strand (2000), Long-distance seed dispersal in plant populations, Am. J. Bot., 87, 1217-1227, doi:10.2307/ 2656714.

Chambers, J. C., and J. A. MacMahon (1994), A day in the life of a seed: Movements and fates of seeds and their implications for natural and managed systems, Annu. Rev. Ecol. Syst., 25, 263-292, doi:10.1146/ annurev.es.25.110194.001403.

Clark, J. S. (1998), Why trees migrate so fast: Confronting theory with dispersal biology and the paleorecord, Am. Nat., 152, 204-224, doi:10.1086/286162.

Clark, J. S., et al. (1998), Reid's paradox of rapid plant migration - Dispersal theory and interpretation of paleoecological records, BioScience, 48, $13-$ 24, doi: $10.2307 / 1313224$.

Clark, J. S., M. Silman, R. Kern, E. Macklin, and J. HilleRisLambers (1999), Seed dispersal near and far: Patterns across temperate and tropical forests, Ecology, 80, 1475-1494.

Clark, J. S., M. Lewis, and L. Horvath (2001), Invasion by extremes: Population spread with variation in dispersal and reproduction, Am. Nat., 157, 537-554, doi:10.1086/319934.

Clauss, M. J., and D. L. Venable (2000), Seed germination in desert annuals: An empirical test of adaptive bet hedging, Am. Nat., 155, 168-186, doi:10.1086/303314.

Clos-Arceduc, M. (1956), Etude sur photographies aeriennes d'une formation vegetale sahelienne: La brousse tigree, Bulletin Inst. Fr. Afr. Noire Ser. A, 7, 677-684.

Couteron, P., and O. Lejeune (2001), Periodic spotted patterns in semi arid vegetation explained by a propagation-inhibition model, J. Ecol., 89, 616-628, doi:10.1046/j.0022-0477.2001.00588.x.

Davidson, D. W., and S. R. Morton (1984), Dispersal adaptations of some acacia species in the Australian arid zone, Ecology, 65, 1038-1051, doi: $10.2307 / 1938312$.

d'Herbes, J. M., C. Valentin, D. J. Tongway, and J.-C. Leprun (2001), Banded vegetation patterns and related structures, in Banded Vegetation Patterning in Arid and Semiarid Environments, edited by D. J. Tongway, C. Valentin, and J. Seghieri, pp. 1-19, Springer, New York.

D'Odorico, P., F. Laio, and L. Ridolfi (2006a), Patterns as indicators of productivity enhancementby facilitation and competition in dryland vegetation, J. Geophys. Res., 111, G03010, doi:10.1029/2006JG000176.

D'Odorico, P., F. Laio, and L. Ridolfi (2006b), Vegetation patterns induced by random climate fluctuations, Geophys. Res. Lett., 33, L19404, doi:10.1029/2006GL027499.

D’Odorico, P., F. Laio, A. Porporato, L. Ridolfi, and N. Barbier (2007), Noise-induced vegetation patterns in fire-prone savannas, J. Geophys. Res., 112, G02021, doi:10.1029/2006JG000261.

Ellner, S., and A. Shmida (1981), Why are adaptations for long-range seed dispersal rare in desert plants?, Oecologia, 51, 133-144, doi:10.1007/ BF00344663. 
Fragoso, J. M. V. (1997), Tapir-generated seed shadows: Scale-dependent patchiness in the Amazon rain forest, J. Ecol., 85, 519-529, doi: $10.2307 / 2960574$.

Fragoso, J. M. V., K. M. Silvius, and J. A. Correa (2003), Long-distance seed dispersal by tapirs increases seed survival and aggregates tropical trees, Ecology, 84, 1998-2006, doi:10.1890/01-0621.

Galle, S., J. Brouwer, and J.-P. Delhoume (2001), Soil water balance, in Banded Vegetation Patterning in Arid and Semiarid Environments, edited by D. J. Tongway, C. Valentin, and J. Seghieri, pp. 77-104, Springer, New York.

Gilad, E. (2004), Ecosystem engineers: From pattern formation to habitat creation, Phys. Rev. Lett., 93, 098105, doi:10.1103/PhysRevLett. 93.098105

Greene, R. S. B., C. Valentin, and M. Esteves (2001), Runoff and erosion processes, in Banded Vegetation Patterns in Arid and Semiarid Environments, edited by D. J. Tongway, C. Valentin, and J. Seghieri, pp. 52-76, Springer, New York.

HilleRisLambers, R., M. Rietkerk, F. van den Bosch, H. H. T. Prins, and H. de Kroon (2001), Vegetation pattern formation in semi-arid grazing systems, Ecology, 82, 50-61.

Howe, H. F., and J. Smallwood (1982), Ecology of seed dispersal, Annu. Rev. Ecol. Syst., 13, 201-228, doi:10.1146/annurev.es.13.110182.001221.

Katul, G. G., A. Porporato, R. Nathan, M. Siqueira, M. B. Soons, D. Poggi, H. S. Horn, and S. A. Levin (2005), Mechanistic analytical models for long-distance seed dispersal by wind, Am. Nat., 166, 368-381, doi: $10.1086 / 432589$

Kefi, S., M. Rietkerk, C. L. Alados, Y. Pueyo, V. P. Papanastasis, A. ElAich, and P. C. de Ruiter (2007a), Spatial vegetation patterns and imminent desertification in Mediterranean arid ecosystems, Nature, 449, 213-217, doi:10.1038/nature06111.

Kefi, S., M. Rietkerk, M. van Baalen, and M. Loreau (2007b), Local facilitation, bistability and transitions in arid ecosystems, Theor. Popul. Biol., 71, 367-379, doi:10.1016/j.tpb.2006.09.003.

Kefi, S., M. Rietkere, and G. Katul (2008), Vegetation patterns shift as a result of rising atmospheric $\mathrm{CO} 2$ in arid ecosystems, Theor. Popul. Biol., in press.

Klausmeier, C. A. (1999), Regular and irregular patterns in semiarid vegetation, Science, 284, 1826-1828, doi:10.1126/science.284.5421.1826.

Lefever, R., and O. Lejeune (1997), On the origin of tiger bush, Bull. Math. Biol., 59, 263-294, doi:10.1007/BF02462004.

Lejeune, O. (2002), Localized vegetation patches: A self-organized response to resource scarcity, Phys. Rev. E, 66, 010901.1-010901.4, doi:10.1103/ PhysRevE.66.010901.

Mauchamp, A., S. Rambal, J. A. Ludwig, and D. J. Tongway (2001), Multiscale modeling of vegetation bands, in Banded Vegetation Patterning in Arid and Semiarid Environments, edited by D. J. Tongway, C. Valentin, and J. Seghieri, pp. 146-166, Springer, New York.

Midgley, J. J. (1998), Dispersibility, cost and allometry of tumblers (Combretum, Combretaceae) and parachutes (Leucadendron, Proteaceae) of different size, Plant Syst. Evol., 211, 141 - 147, doi:10.1007/BF00985355.

Montana, C., J. Seghieri, and A. Cornet (Eds.) (2001), Vegetation Dynamics: Recruitment and Regeneration in Two Phase Mosaic, 1st ed., Springer, New York.

Murray, J. D. (2002), Mathematical Biology, Springer, New York.

Prasse, R., and R. Bornkamm (2000), Effect of microbiotic soil surface crusts on emergence of vascular plants, Plant Ecol., 150, 65-75, doi:10.1023/A:1026593429455.

Reichman, O. J. (1984), Spatial and temporal variation of seed distributions in Sonoran Desert soils, J. Biogeogr., 11, 1-11, doi:10.2307/2844771.
Rietkerk, M., and J. van de Koppel (2008), Regular pattern formation in real ecosystems, Trends Ecol. Evol., 23, 169-175, doi:10.1016/ j.tree.2007.10.013.

Rietkerk, M., M. C. Boerlijst, F. van Langevelde, R. HilleRisLambers, J. van de Koppel, L. Kumar, H. H. T. Prins, and A. M. de Roos (2002), Selforganization of vegetation in arid ecosystems, Am. Nat., 160, 524-530, doi: $10.1086 / 342078$.

Rietkerk, M., S. C. Dekker, P. C. de Ruiter, and J. van de Koppel (2004), Self-organized patchiness and catastrophic shifts in ecosystems, Science, 305, 1926-1929, doi:10.1126/science.1101867.

Russo, S. E., S. Portnoy, and C. K. Augspurger (2006), Incorporating animal behavior into seed dispersal models: Implications for seed shadows, Ecology, 87, 3160-3174, doi:10.1890/0012-9658(2006) 87[3160:IABISD]2.0.CO;2.

Scholes, R. J., and S. R. Archer (1997), Tree-grass interactions in savannas, Annu. Rev. Ecol. Syst., 28, 517-544, doi:10.1146/annurev.ecolsys.28.1.517.

Thiery, J. M., J. M. Dherbes, and C. Valentin (1995), A model simulating the genesis of banded vegetation patterns in Niger, J. Ecol., 83, 497507, doi: $10.2307 / 2261602$.

Thiery, J. M., D. Dunkerley, and B. Orr (2001), Landscape models for banded vegetation genesis, in Banded Vegetation Patterning in Arid and Semiarid Environments, edited by D. J. Tongway, C. Valentin, and J. Seghieri, pp. 167-197, Springer, New York.

Thiombiano, A., R. Wittig, and S. Guinko (2003), Conditions of sexual multiplication in some Combretaceae in Burkina Faso, Rev. Ecol. (Terre Vie), 58, 361-379.

Thompson, S., and G. G. Katul (2008), Plant propagation fronts and wind dispersal: An analytical model to upscale from seconds to decades using super-statistics, Am. Nat., 171, 468-479.

Tongway, D. J., and J. A. Ludwig (2001), Theories on the origin, maintenance, dynamics and functioning of banded landscapes, in Banded Vegetation Patterning in Arid and Semiarid Environments, edited by D. J. Tongway, C. Valentin, and J. Seghieri, pp. 20-31, Springer, New York.

Ursino, N. (2005), The influence of soil properties on the formation of unstable vegetation patterns on hillsides of semiarid catchments, Adv. Water Resour., 28, 956-963, doi:10.1016/j.advwatres.2005.02.009.

Ursino, N. (2007), Modeling banded vegetation patterns in semiarid regions: Interdependence between biomass growth rate and relevant hydrological processes, Water Resour. Res., 43, W04412, doi:10.1029/2006WR005292.

Ursino, N., and S. Contarini (2006), Stability of banded vegetation patterns under seasonal rainfall and limited soil moisture storage capacity, $A d v$. Water Resour., 29, 1556-1564, doi:10.1016/j.advwatres.2005.11.006.

Valentin, C., J. M. d'Herbes, and J. Poesen (1999), Soil and water components of banded vegetation patterns, Catena, 37, 1-24, doi:10.1016/ S0341-8162(99)00053-3.

van der Pijl, L. (1972), Principles of Dispersal in Higher Plants, SpringerVerlag, Berlin.

von Hardenberg, J., E. Meron, M. Shachak, and Y. Zarmi (2001), Diversity of vegetation patterns and desertification, Phys. Rev. Lett., 87, 198101.1-198101.4.

Yizhaq, H., E. Gilad, and E. Meron (2005), Banded vegetation: Biological productivity and resilience, Physica A, 356, 139-144.

G. Katul, S. M. McMahon, and S. Thompson, Nicholas School of the Environment and Earth Sciences, Duke University, Box 90328, Durham, NC 27708, USA. (gaby@duke.edu; seanmcm@duke.edu; set8@duke.edu) 